\title{
Ensino-Aprendizagem de Programação utilizando Storytelling na Educação Infantil
}

\author{
Franciely Alves de Souza \\ Universidade Federal Rural de Pernambuco \\ Recife, Pernambuco, Brasil \\ francielyalves835@gmail.com
}

\author{
Maria Renay Barbosa da Silva \\ Universidade Federal de Pernambuco \\ Recife, Pernambuco, Brasil \\ renaybarbosa@gmail.com
}

Quando a aula passa a ser inserida no contexto no qual os alunos já estão habituados, se torna mais fácil despertar o interesse e a curiosidade. Dessa forma, é possível criar cenários que podem ser utilizados como narrativas para tornarem as aulas mais atrativas e lúdicas.

O ensino de programação nas escolas é de grande importância, por possibilitar o desenvolvimento de várias habilidades que podem ajudar na realização de tarefas do cotidiano, sendo: raciocínio lógico, capacidade de resolução de problemas, criatividade, comunicação e trabalho em equipe.

Este trabalho teve como objetivo analisar como as narrativas podem contribuir para a motivação de estudantes da educação infantil, no aprendizado de programação em blocos.

De acordo com [3] as narrativas são bastante utilizadas na educação, principalmente nos primeiros anos da educação básica, quando tem papel fundamental para o desenvolvimento da imaginação, senso crítico, personalidade, atenção, memória, observação e reflexão de crianças.

Pop-up são apreciados por crianças e adultos, e podem assumir propósitos pedagógicos, lúdicos e até mesmo artísticos [4]. De acordo com [2] explora uma narrativa infantil sob diferentes mídias, pode tornar a experiência de aprendizagem de computação mais envolvente para crianças. Sabendo dessa maior facilidade de se compreender conteúdos apresentados de forma interativa, os conceitos de programação se tornam mais interessantes utilizando a parte física em pop-up juntamente com a narrativa por meio do storytelling.

Segundo [1] o Scratch Jr é uma linguagem de programação introdutória que encoraja a criatividade e a criação de projetos interativos. A programação é construída de acordo com os encaixes de blocos que programam as ações dos personagens, fazendo com que eles se movimentem, cantem, saltem e entre outros.

A experiência relatada neste trabalho ocorreu no ano de 2020 , tendo vinte alunos como participantes, e ocorreu durante o período de aulas remotas. Onde foi encontrada a dificuldade de trabalhar conceitos de programação por aulas online e vídeo aulas. Em meados de 2020 ocorreu uma desmotivação dos alunos em relação as aulas de programação. Pensando em soluções para motivar e tornar a aprendizagem lúdica, foram utilizadas técnicas de atividades físicas e contação de histórias.

Fica permitido ao(s) autor(es) ou a terceiros a reprodução ou distribuição, em parte ou no todo, do material extraído dessa obra, de forma verbatim, adaptada ou remixada, bem como a criação ou produção a partir do conteúdo dessa obra, para fins não comerciais, desde que sejam atribuídos os devidos créditos à criação original, sob os termos da licença CC BY-NC 4.0.

EduComp'21, Abril 26-30, 2021, Jataí, Goiás, Brasil (On-line)

(c) 2021 Copyright mantido pelo(s) autor(es). Direitos de publicação licenciados à

Sociedade Brasileira de Computação (SBC).
Os alunos passaram a produzir atividades PopUp como forma de engajamento, já que a utilização de matérias físicos é fundamental para despertar a criatividade de alunos ainda na educação infantil. As produções Pop-Up eram produzidas a partir de uma pequena narrativa explicativa sobre o que precisava ser produzido, após toda a construção e tendo a narrativa em mente, era proposta para os alunos a utilização da ferramenta Scratch Jr para programar a história que foi construída por meio do Pop-Up.

Através dessa estratégia de ensino, foi perceptível que os alunos se tornaram mais engajados e criativos ao pensar na solução para um problema a partir de uma narrativa lúdica e intuitiva

A utilização do storytelling foi fundamental para resgatar o interesse dos alunos pelos conceitos de programação, a cada nova atividade sempre surgia a especulação de qual seria a narrativa utilizada para a construção do Pop-Up, desta forma proporcionando para os alunos uma aprendizagem de programação divertida e atrativa. Como trabalhos futuros a intenção é utilizar as narrativas no ensino fundamental, a fim de engajar os alunos na aprendizagem de programação.

\section{REFERENCIAS}

[1] Marina Umaschi Bers and Mitchel Resnick. 2015. The official Scratchfr book: Help your kids learn to code. No Starch Press.

[2] Rozelma Soares de França. 2020. Uma abordagem pedagógica incorporada para o desenvolvimento do pensamento computacional no ensino fundamental. Retrieved Mar 4, 2020 from https://repositorio.ufpe.br/handle/123456789/38542

[3] Pedro Mello Amado dos Santos. 2016. Storydoing: melhor que contar é fazer, um novo olhar sobre a Disney. https://repositorio.uniceub.br/jspui/handle/235/9504 Monografia (Graduação) - Faculdade de Tecnologia e Ciências Sociais Aplicadas, Centro Universitário de Brasília, Brasil.

[4] Jean-Charles Trebbi. 2013. El arte del pop-up. Promopress. 